\title{
PNEUMATOLOGÍA, PAISAJE Y CULTO: PATRONES ANDINOS EN LOS PROCESOS DE ANCESTRALIZACIÓN DE LA CULTURA MAPUCHE WILLICHE EMPLAZADOS EN LA NATURALEZA
}

\author{
PNEUMATOLOGY, LANDSCAPE AND WORSHIP: \\ ANDEAN PATTERNS IN MAPUCHE WILLICHE ANCESTRALIZATION \\ PROCESS EMPLACED IN NATURE
}

\author{
Rodrigo Moulian ${ }^{1}$ y Pablo M. Espinoza C. ${ }^{2}$
}

\begin{abstract}
En la cultura mapuche williche se encuentran vigentes una serie de variantes en los procesos de ancestralización, a través de los que las personas devienen en espíritus situados en la naturaleza, cuyos rasgos resultan comunes al mundo andino. La captura por espacios intersticiales y poderosos, el enamoramiento de entidades numinosas que habitan en estos lugares o el castigo recibido por parte de estas entidades sobrenaturales son algunas de las vías alternativas que pueden conducir a la transformación en ancestros topográficamente emplazados. Estos eventos, que constituyen motivos míticos recurrentes en las áreas centro y sur andinas, dejan ver la comunidad de patrones cosmovisionarios en torno a las representaciones pneumatológicas, las concepciones del paisaje y formas de culto a los espíritus ancestrales a lo largo de los Andes.
\end{abstract}

Palabras claves: andinidad, cosmovisión, ancestralización, paisaje, culto.

In the Mapuche-Williche culture there are a set of variants in ancestralization processes, through which people become spirits emplaced in nature, and whose features are common to the Andean world. The capture by interstitial spaces, the falling in love with numinous entities that inhabit these places, or the punishment inflicted by these supernatural entities, are some of the alternative ways that can lead to topographically situated ancestor transformation. These mythical motifs, which are recurring events in the central and southern Andean areas, show the community of worldview patterns around pneumatological representations, conceptions of landscape and forms of worship of spirits, along this space.

Key words: Andeanness, worldview, ancestralization, landscape, worship.

La discusión sobre los vínculos de la cultura mapuche williche con el mundo andino tiene una larga data, pero una posición relativamente marginal en la antropología chilena. En las primeras décadas del siglo pasado, Tomás Guevara (1911) postuló el origen peruano del sistema religioso cosmovisionario mapuche williche. De acuerdo con el autor, los mapuche habrían adoptado de los incas los componentes animistas, naturalistas, totémicos y mágicos de su religión. No obstante, su tesis sobre la acción aculturadora del incario no resiste un análisis etnohistórico, por la reducida extensión temporal y alcance geográfico del mismo, que se estima entre 1471 y 1536 (Silva 1977-1978) y llega hasta el río Maule. Al sur de este, los incas han mantenido relaciones culturales y comerciales y probablemente asentamientos temporales dispersos (Dillehay y Gordon 1988), pero su influencia es mucho más porosa y transitoria.

El primado del particularismo histórico y cultural que se establece con la institucionalización académica de la antropología en el país, a partir de la década de 1960, ha relegado desde entonces el estudio de las relaciones interculturales de los pueblos originarios. Una excepción relevante se encuentra en el trabajo de María Ester Grebe, quien, desde mediados de los años ochenta, desarrolló un programa comparativo de patrones cognitivos mapuche, aymara y atacameños (Grebe 1986, 19951996, 1996, 2002). De acuerdo con esta investigadora, las concepciones mapuche del tiempo y del espacio, sus patrones de movimiento ritual, el dualismo en

1 Instituto de Comunicación Social, Universidad Austral de Chile. Casilla 567 Valdivia, Chile. rmoulian@ hotmail.com

2 Departamento de Español, Universidad de Tarapacá. Casilla 6-D, Arica, Chile. pespinozac@uta.cl 
los procesos de simbolización y la creencia en los espíritus de la naturaleza presentes en su religión son andinos. Estos rasgos culturales expresarían una filiación identitaria de origen de este pueblo y habrían llegado junto a sus portadores al momento de desplazarse al sur de Chile. No obstante, la tesis migratoria que suscribe no se encuentra avalada por más evidencia empírica que las analogías culturales. La misma no es consistente con los datos arqueológicos, que informan de la continuidad del poblamiento del espacio centro y sur de Chile de los últimos 12.500 años (Adán et al. 2004; Dillehay 2004), ni con los antecedentes etnohistóricos, que registran la unidad lingüística y cosmovisionaria de la población prehispánica asentada entre el río Maipo y la isla grande de Chiloé, al momento de la conquista.

Una tesis alternativa para explicar los correlatos cosmovisionarios expuestos por estos autores es el carácter persistente de las interacciones culturales en el espacio centro-sur andino. Con una perspectiva metodológica transdisciplinaria, el trabajo de Tom Dillehay $(1990,1998,2011)$ apunta en esta dirección. Su investigación expone las correlaciones andinas de los patrones rituales espaciales, simbolismos animales y monumentos funerarios mapuche, describiendo un rango de afinidades que van desde los modelos espaciales de Chavín a los patrones de organización cúltica del Tawantinsuyo. El presente trabajo sobre el devenir la persona en ancestro en la cultura mapuche williche, transustancializado en elemento de la naturaleza, se sitúa en esta línea explicativa. Por medio del análisis de tramas de simbólicas que expresan paradigmas cosmovisionarios mostramos paralelismos culturales de carácter panandino que, por su extensión y complejidad, se deben haber labrado en relaciones de larga data y que presentan continuidad en el tiempo.

\section{Ngen Mapu}

El culto a espíritus ancestrales emplazados en el paisaje es uno de los componentes distintivos de la religiosidad mapuche williche. Su fenomenología se encuentra comprendida en la bibliografía etnográfica bajo el concepto de "mediadores" (Foerster 1993; Foerster y Gunderman 1996). Se trata de espíritus personales que actúan como intercesores ante las deidades. Entre estos destacan el Abuelito Wenteyao de Pucatrihue; Mankeante en Toltén;
María Guacolda de Lumaco; Kintuante de Maihue Carimallín y Juanico de Nolguehue. En mapudungun se los denomina ngille mapu (Álvarez-Santullano y Contreras 1991) por ser a quienes "se ruega en la tierra", o ngen mapu, es decir, "dueños del territorio" (Moulian 2008), por considerarlos espíritus tutelares del espacio. En castellano se los califica como "encantados", aludiendo a la intervención de un poder sobrenatural que ha actuado sobre ellos para definir su destino.

Los ngen mapu, como se les conoce genéricamente, poseen características que los distingue de otras entidades espirituales que forman parte del complejo campo de las representaciones pneumatológicas mapuche williche ${ }^{1}$. Entre estos rasgos diferenciadores se encuentran: (i) su carácter personalizado y reconocimiento ancestral, por ser sujetos mapuche que han devenido en espíritus; (ii) el haber adquirido esta condición a través de una metamorfosis y transustanciación; (iii) su emplazamiento en el paisaje de manera permanente, lo que hace posible el acceso físico a ellos; (iv) el estar revestidos de un poder sobrenatural; y (v) servir de mediadores entre las personas y las divinidades.

Los rasgos polares de ancestralidad y naturalización los describen sintéticamente. Se trata de espíritus poseedores de una historia biográfica humana que los vincula a las comunidades y que han adquirido una condición numinosa derivada de su situación liminar, en tanto han trascendido el plano temporal y los límites de este mundo, pero se encuentran simultáneamente en él, constituidos en hitos del paisaje, radicados en estos puntos intersticiales que-se considera-comunican las distintas dimensiones del mundo (Figura 1).

En la mayoría de los casos, sus moradas se encuentran emplazadas en el entorno de las comunidades, asociadas a accidentes naturales como cuevas, rocas o vertientes, que constituyen centros de peregrinaje de las congregaciones rituales indígenas. En ellas, se cree, existen puertas que conectan las diversas dimensiones del universo mapuche (Wenu Mapu, Nag Mapu y Minche Mapu), cuyos planos allí se trasponen y sintetizan, permitiendo el tránsito y establecimiento de estos espíritus ancestrales y el devenir de las personas en espíritus. Por lo mismo, quienes concurren a estos lugares lo hacen con cuidado y respeto.

Por su carácter tutelar, su culto marca la identidad de los miembros de las congregaciones rituales. 


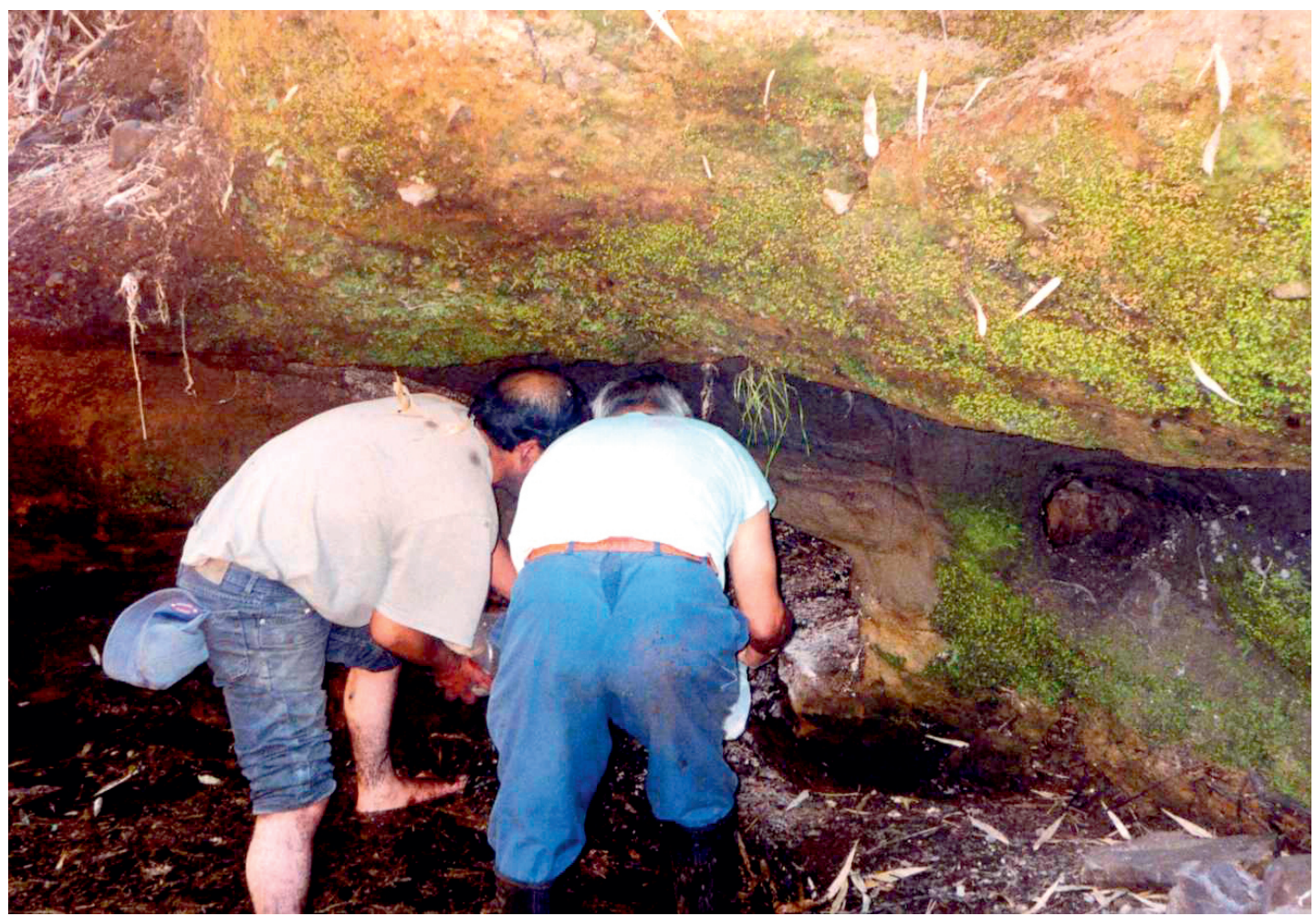

Figura 1. Renü (cueva) donde habita Juanico, espíritu tutelar de la Comunidad de Nolguehue. Renü (cave) where Juanico, the tutelary spirit of the Nolguehue community, dwells.

En la cuenca del río Bueno, los que participan en ellas se denominan a sí mismos kamaskos. En la actualidad constituyen un grupo minoritario dentro de sus comunidades, compuesto por los mayores o cabezas de no más de veinte grupos familiares en Pitriuco (donde veneran al Abuelo Wenteyao), nueve familias en Nolguehue (morada de Juanico) y ocho en Maihue Carimallín (donde se rinde culto a Kintuante). Ellos son los encargados de mantener, resguardar y solventar las prácticas religiosas tradicionales, en un contexto que no se muestra favorable, porque se encuentra expuesto a profundos procesos de aculturación, que incluye la pérdida del manejo de la propia lengua. Para llevar adelante su tarea disponen de una organización basada en cargos, dirigida por un maestro de ceremonias, una kamaska mayor, un capitán, sargentos y bastoneros, cuya autoridad se activa solo en el período de desempeños rituales, que en esta área suele tener una periodicidad anual.

Los datos sobre la adscripción religiosa de las comunidades indígenas de la cuenca del río Bueno, donde se sitúan estas comunidades, revelan la intensidad de los procesos de cambio social en el área. En ellas el $45,1 \%$ de su población mayor de 15 años se declara evangélica, el 40,56\% se asume católica y solo el 5,24 se define como cultora de la religiosidad mapuche (Moulian 2012). Muchos de los kamaskos son católicos. No obstante, en el marco de conflictos medioambientales que amenazan los espacios sagrados, algunas de estas congregaciones indígenas han vivido procesos de reetnificación y de radicalización étnica. El culto a lo Ngen Mapu oscila aquí entre la supervivencia y la resistencia. Muy distinto del caso de María Guacolda, en Lumaco, porque su morada se sitúa en una zona donde la lengua y la cultura mapuche mantienen vitalidad. Difiere también en que su liturgia descansa en la vocación de varias machi, como se conoce a las o los chamanes mapuche, que asisten con sus equipos de trabajo ritual. No tiene un carácter congregacional, sino personalizado. A él asisten cientos de peregrinos de manera individual, atraídos por la fama de su newen o su poder vitalizante (Figura 2).

La tradición oral mapuche preserva y reproduce una rica narrativa que registra la historia de estos 


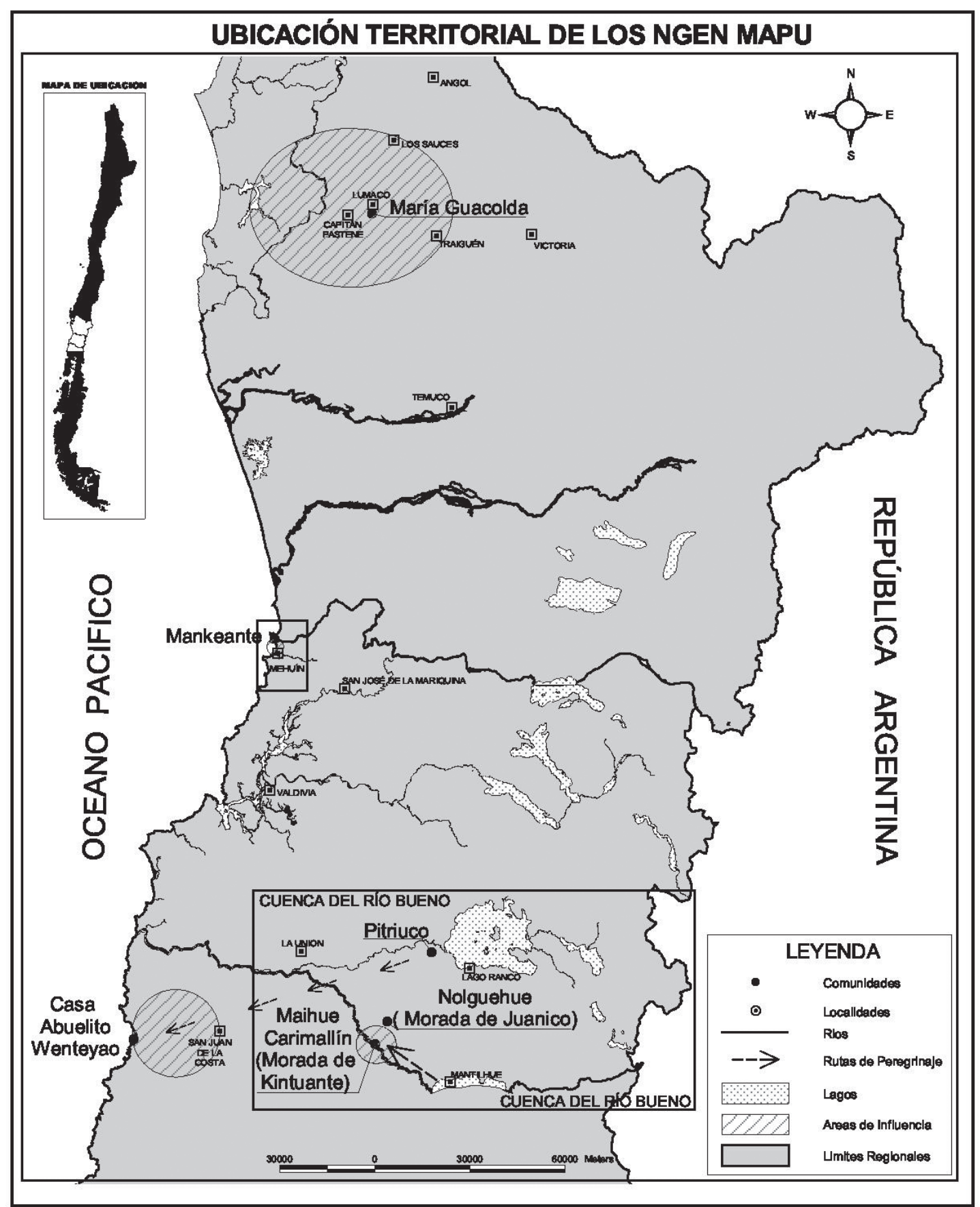

Figura 2. Mapa del territorio donde se ubican los ancestros mapuche williche emplazados en la naturaleza. Map of the territory where the Mapuche Williche ancestors emplaced in nature are located.

personajes a los que se rinde culto, las condiciones en las que han devenido en espíritus y las manifestaciones de su poder, que se tienen como la relación de hechos reales. Existe en la actualidad disponible un amplio repertorio de relatos de no ficción, conocidos como nütran, que informan de los procesos de ancestralización y el culto a los espíritus emplazados en el paisaje (Carrasco 1989; Foerster 1993; Gissi 1997; Quezada 2002; Schindler y Schindler 2006). Estas narrativas 
circulan en las comunidades por medio de las conversaciones familiares que forman parte de la socialización primaria. La memoria mítica que ellos expresan es el fundamento de las prácticas rituales vigentes que actualizan y mantienen vivas las representaciones cosmovisionarias mapuche williche. Sus etnomodelos activan competencias, regulan desempeños y se despliegan en patrones de acción que dan forma a la experiencia humana.

Nuestra investigación se nutre tanto de fuentes literarias como etnográficas, pero ha sido el trabajo de campo nuestra primera y principal vía de acceso a la información que aquí exponemos (Moulian 2005, 2012; Moulian y Valdés 2001). Entre 1998 y 2008 hemos realizado observación participante en varias congregaciones rituales mapuche williche que le rinden cultos a diversos espíritus ancestrales emplazados en el paisaje ${ }^{2}$. Este ejercicio desembocó en un estudio específico sobre el culto a los $\mathrm{Ngen}$ Mapu en la cuenca del río Bueno (Moulian 2008), que analiza de manera focalizada su sistema de representaciones y prácticas rituales. El proyecto de investigación que actualmente se desarrolla ha permitido extender el trabajo etnográfico hasta el espacio centro andino, donde se advierten paralelismos sistemáticos en torno a los procesos de ancestralización.

\section{Tramas Culturales}

El culto a los espíritus ancestrales mapuche williche emplazados en la naturaleza muestra el entramado semiótico de la cultura. Este constituye un complejo simbólico donde convergen representaciones y prácticas pertenecientes a diversas dimensiones de su sistema cosmovisionario, como son la pneumatología (fenomenología del espíritu), las concepciones del paisaje, la cosmología o concepción del universo y la liturgia u orden del culto. Si bien entre sus componentes se encuentran imágenes arquetípicas (Eliade 1970; Jung 1994) y símbolos cuya significación se constituye sobre la base de relaciones de tipo indexal (Peirce 1974) y son, por lo tanto, naturales, estos elementos se encuentran articulados en tramas simbólicas que expresan el trabajo de urdimbre propio del tejido cultural. Las variantes textuales de este complejo cúltico muestran no solo una gramática simbólica, sino órdenes de representación. En su textura se expresan paradigmas cosmovisionarios, es decir, metamodelos, modelos de modelos por medio de los que se organiza la lectura del mundo, gracias a los que este adquiere un particular sentido. Las analogías que reseñamos no pueden, por lo tanto, explicarse según las teorías naturalistas de los autores previamente referidos, pues su complejidad es la de la urdimbre cultural ${ }^{3}$.

En el caso de los Ngen Mapu llama la atención que las cualidades personales de los protagonistas no inciden de manera decisiva en su devenir en ancestros. Estos no son seleccionados por encarnar valores culturales que se desee exaltar, por poseer una posición privilegiada en la estructura social cuyos fundamentos se intente legitimar o exhibir una conducta ejemplar que se promueva. Por lo general, se trata de personas comunes cuyo destino se define por una agencia exterior a ellos, que en muchas ocasiones actúa por sobre el arbitrio de su voluntad. La transformación en ancestros se presenta, así, como una situación potencialmente extensible a cualquiera que experimente las mismas circunstancias. Su casuística asume un carácter pedagógico, pues muestra de manera ejemplar la integración de las tramas simbólicas que debe manejar un miembro del grupo cultural.

Sobre el particular distinguimos tres variantes en los procesos de ancestralización: (a) la captura de las personas por espacios poderosos capaces de absorber su energía anímica, pero también de irradiar fuerza vital, (b) el enamoramiento de entidades espirituales que habitan en ellos, y (c) el castigo recibido por parte de estas entidades. Estas alternativas exponen patrones que son comunes al mundo central andino, los que se encuentran ampliamente registrados en su narrativa mítica (Taylor 1987; Urbano 1981; Villanés 1992). Su vigencia se muestra en la continuidad de las prácticas rituales desarrolladas por los habitantes de los Andes. Si bien en este espacio ellas no constituyen las únicas vías de ancestralización ${ }^{4}$ (Kaulicke 2003; Nielsen 2010; Salomon 1995) ni las únicas formas de ancestralización de la naturaleza $^{5}$ (Jemio 2009; Martínez 1976), el culto a los antepasados emplazados en el paisaje pone en evidencia la comunidad de paradigmas cosmovisionarios en las áreas Centro y Sur Andina. La constatación de paralelismos en estas tramas simbólicas (secuencias de puntos que se mueven en la misma dirección) que comprometen los diversos niveles de la semiosis (sintáctico, semántico y pragmático) devela un correlato en los sistemas culturales. 


\section{Paisajes Numinosos}

En la particularidad del caso mapuche, la producción de los ancestros se presenta como la manifestación de fuerzas asentadas en los espacios naturales, dotadas de una capacidad transformadora, que modifica el destino y la condición de los seres humanos. Las tramas simbólicas del culto a los ngen mapu, por lo tanto, no solo ponen en escena las concepciones pneumatológicas, sino las representaciones culturales del paisaje a cuyas propiedades y/o entidades se atribuye la agencia en los procesos de ancestralización.

Si bien la narrativa mapuche williche sobre los Ngen Mapu se presenta siempre como un sistema de transformaciones, que ofrece diversas versiones, se pueden distinguir en ella motivos constantes, argumentos preferentes y tópicos recurrentes del proceso de devenir en ancestro. Entre estos se encuentran: (a) la desaparición o transformación de los protagonistas, que se pierden en el entorno de sus comunidades sin dejar rastro, (b) la revelación de su destino trascendente, y (c) la solicitud e institucionalización de culto.

Con excepción de la historia de Mankeante, en la que hay testigos de su transformación en piedra, en los otros cuatro casos referidos, la pérdida de los protagonistas es el primer indicio de una situación anómala. Se trata de un acontecimiento particularmente perturbador para la cultura mapuche, porque una eventual muerte exige una serie de ritos que aseguren el paso de los espíritus a la otra vida (Schindler 1996). De este modo se evita que las almas queden vagando y sean capturadas por los brujos. Por lo mismo, ante una desaparición se acude a las machi pelontufe (agentes mágicos visionarios) para aclarar la situación. Por medio de sus invocaciones y el reconocimiento del espacio, son capaces de develar el destino espiritual de los sujetos extraviados e identificar de modo preciso su nueva morada.

Luego, los espíritus solicitan a las machi o a los propios familiares, con quienes se comunican por sueños, revelaciones o apariciones, que no los olviden y les informan que están allí para ayudarles mientras permanezcan en este mundo. Se constituye así el culto a los espíritus ancestrales emplazados en el entorno, generalmente en accidentes naturales, que para las comunidades constituyen espacios numinosos (Otto 2001), es decir, lugares revestidos de poder, que suscitan respeto y temor, los que, a su vez, son hitos topográficos y culturales patrimonializados.

\section{Espacios Liminales}

Los Ngen Mapu Kintuante y Juanico ilustran la primera de las variantes de los procesos de ancestralización que hemos distinguido. Sus residencias se encuentran emplazadas en pequeñas cavidades subterráneas localizadas en las comunidades Maihue Carimallín y Nolguehue, correspondientes a la comuna de Río Bueno, Región de Los Ríos. Se trata de personas capturadas por espacios intersticiales. Sus espíritus se encuentran contenidos en renü. Con este término se denomina a las cuevas, que los diccionarios del mapudungün caracterizan como lugar de reunión de hechiceros (Augusta 1992 [1916]). No obstante, el sentido etimológico de este etnónimo es distinto. El lexema se compone de las voces " $r$ " (cuya denotación es "puro", "auténtico" y connota lo sagrado) y "nün" (que significa 'coger', 'agarrar', 'tomar'). La voz "renü" se puede traducir como "tomado por lo sagrado', lo que explica la reivindicación y patrimonialización de estos espacios por parte de las comunidades, que demandan su reconocimiento y protección como lugares con valor religioso y cultural (Comisión de Trabajo Autónomo mapuche 2003).

Kintuante es un hombre de edad madura que desaparece cuando buscaba nalcas en los márgenes del río Pilmaiquén. Juanico es un kona (soldado mapuche) que se pierde tras esconderse de los españoles en una cueva en la ribera del río Muticao. Ambos son capturados por los renü que se transforman desde entonces en sus moradas eternas. Si bien estos son espacios subterráneos, funcionan como puertas que conducen hacia el Wепи Мари, la tierra de arriba, morada de las deidades. La condición de los Ngen Мари es la de espíritus liminares, que se desplazan entre las diversas dimensiones del universo mapuche, pero no por decisión, vocación u opción, sino por agencia del paisaje que los abduce y contiene. Los renü se presentan así como lugares intersticiales y numinosos.

Nos encontramos aquí con un rasgo común a los Andes, donde el paisaje se encuentra revestido de una geografía sagrada (Martínez 1976, Regalado 1996), la que se caracteriza por la presencia de "mundos permeables y espacios peligrosos" (Cruz 2006). En el territorio se proyectan y confluyen las diversas dimensiones de universo cogitado, de modo que su topografía expone los modelos cosmográficos. Así, por ejemplo, el término konün wenu designa en mapudungun a las entradas al espacio de arriba 
o Wenи Мари. Entre las formas que pueden asumir estas se encuentran los renü (cuevas), los menoko (pantanos), los relmü (arcoíris) (Moulian 2008), dewiñ (volcanes), trolol mamül (el tronco de los árboles) (Koessler 1962). Los rewe, instrumentos o espacios diseñados para la interacción entre los seres humanos, espíritus y las deidades, permiten, igualmente, tender puentes entre las diversas dimensiones del universo mapuche. Cruz (2006) destaca el papel de los punku (portales, pasos de montaña) y qaqa (piedras) como vasos comunicantes entre los mundos en la zona de Potosí. No obstante, la fenomenología de los mismos en el mundo central andino es mucho más amplia si se considera las paqarina (lugares de origen) a través de las que se mueven los espíritus y las waka (espacios donde se manifiesta el poder vitalizante), los que pueden situarse en cocha (lagunas), pukio (manantiales), chinkana (cuevas), además de piedras.

La literatura tradicional andina presenta un amplio registro de estos lugares "encantados" donde se aparecen diversos tipos de entidades sobrenaturales y las personas desaparecen (Condori y Gow 1976; Sebastiani 1989; Taype et al. 2011; Toro 2007). Su rol en los procesos de ancestralización se encuentra consignado tempranamente por los cronistas de la conquista que informan del mito de los hermanos del Ayar y el origen de los incas. Al sentarse sobre una waka en el cerro Huanacuri, situado fuera de Cusco, Ayar Uchu se ve abrazado por la piedra y queda petrificado (Sarmiento de Gamboa 2001), transformándose en una de las principales waka del Tawantinsuyo. En San Damián, provincia de Huarochiri, ubicada al este de Lima, podemos ver la vigencia de este tipo de representaciones. Allí los habitantes del poblado de Conchasica rinden culto a los espíritus de Pedro Batán y Mama Capiama, a los que recuerdan como antiguos habitantes desaparecidos en la laguna de Yasanacocha, donde ahora se encargan de cuidar las aguas del pueblo (Vera 2002). Todos los años los comuneros de este lugar les rinden cultos como "dueños del agua" y propiciadores de la abundancia de este recurso fundamental para la vida (Salomon 1998).

\section{Culpa de Amores o Imprudencias}

Wenteyao y María Guacolda son los mediadores ancestrales cuyo culto se encuentra más difundido en la cultura mapuche, alcanzando un carácter regional. El nombre del primero es invocado en las comunidades Williche del área sur de la Región de Los Ríos y el norte de la Región de Los Lagos. Hasta su morada se desplazan cada año varias congregaciones rituales, principalmente de la comuna de San Juan de la Costa, en fecha previa a la realización de sus rogativas comunitarias. El propósito de su viaje ritual es propiciar la presencia espiritual de Wenteyao en sus ceremonias. Por su parte, María Guacolda concita el mayor peregrinaje ritual vigente en el mundo mapuche, que moviliza a personas de las regiones del Biobío y de La Araucanía, cada 19 de enero. Su celebración ha devenido en una fiesta popular tumultuosa, que se extiende por toda la noche, donde junto al purun de las machi es posible bailar rancheras.

Sus casos ilustran la segunda de las variantes en los procesos de ancestralización, donde los protagonistas se convierten en espíritus al entrar en amores con entidades sobrenaturales que habitan en los espacios numinosos. De acuerdo con la tradición oral, la acción visionaria de agentes religiosos (machi) o la revelación espiritual han permitido conocer su destino trascendente. Así se sabe que el Abuelito Wenteyao se enamoró de una sumpall (sirena) y reside en las rocas de Pucatrihue (Quezada 2002), que constituyen su morada. María Guacolda o Kulüwa (maíz rojo), en tanto, vive en una piedra conocida como Amunkura (la piedra que anda), situada en Lumaco, donde ha encontrado marido y formó familia (Sofía Painequeo comunicación personal 2012) (Figura 3).

Las formas líticas son aquí significantes de la presencia espiritual, que tiene en las piedras residencia o su propia existencia, producto de una litomorfosis. Este constituye un motivo ampliamente difundido en el mundo andino (Duviols 1973, Galdames 1987), que también marca a la cultura mapuche (Cañas 1909). El libro Ritos y Tradiciones de Huarochiri (Taylor 1987) muestra extensamente el programa de la litificación vinculado a la producción de ancestros espirituales (Rubina 1992), entre cuyas variantes se encuentra la entrada en amores con waka, como se denomina a las entidades sobrenaturales. Así sucede con Chuquisuso, hermosa mujer del pueblo de San Lorenzo, quien accede a ser amante de Pariacaca para garantizar el agua de su comunidad y queda convertida en piedra en la acequia de Cocochalla (Taylor 1987). No obstante, como hemos mostrado, las formas líticas no son el único significante del espíritu. El mismo libro del Huarochiri registra 


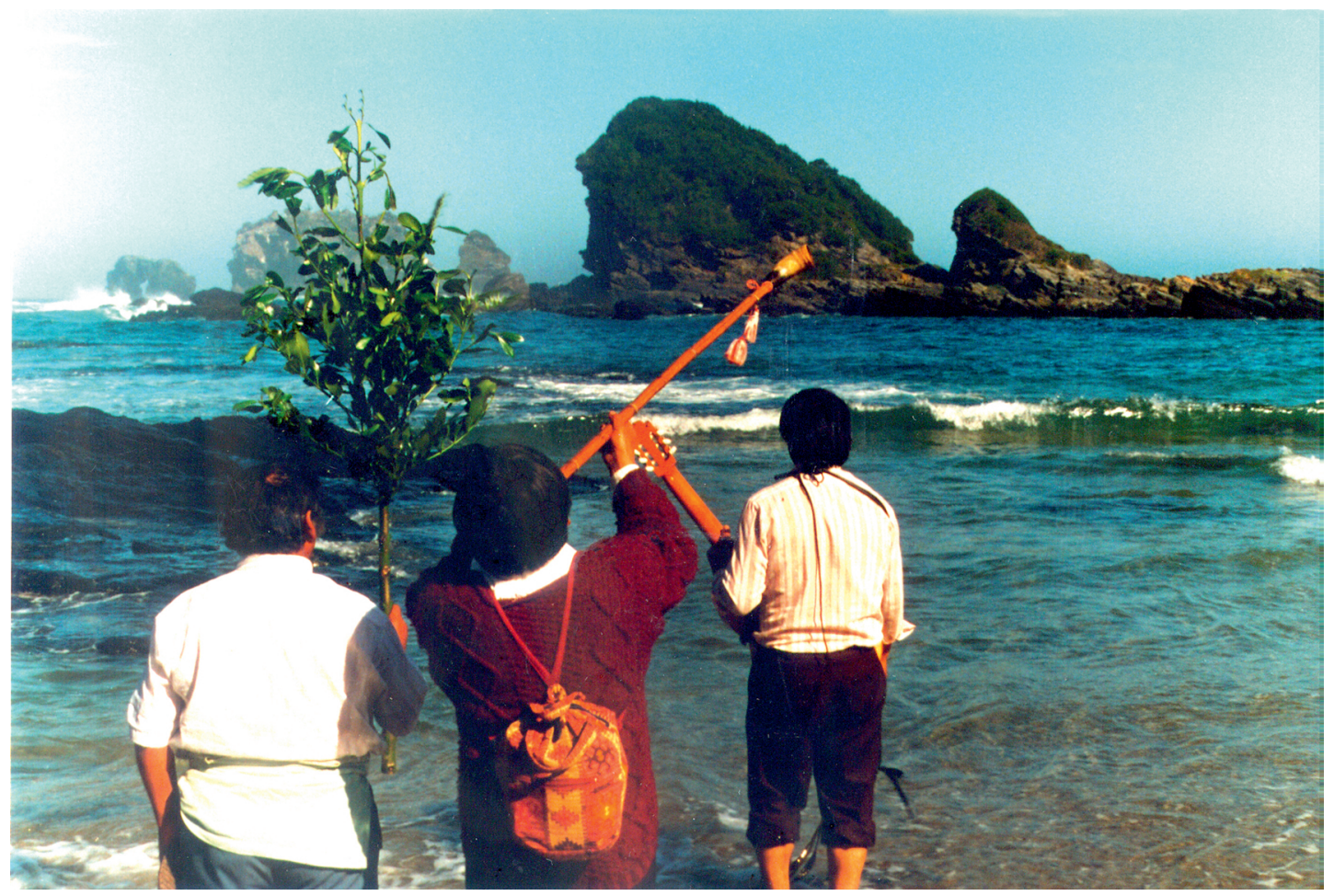

Figura 3. Peregrinaje a la casa de Abuelito Wenteyao en las rocas de Pucatrihue.

Pilgrimage to the house of Grandpa Wenteyao in the rocks of Pucatrihue.

una versión donde la joven Capiama se enamora del waka Collquirí y se transforma en el agua de una laguna.

Mankeante es el espíritu tutelar de la población Lafkenche (costera) de las comunas de Mariquina y Toltén. Su historia ejemplifica la tercera variante que hemos distinguido en los procesos de ancestralización, donde esta nueva condición se adquiere como resultado de una sanción. Según el relato registrado por Alonqueo (1993), su protagonista, Juan Mankeante, antiguo cacique gobernador de Mariquina, es castigado por faltarle el respeto a un ngenko (espíritu dueño de un manantial), que lo transforma progresivamente en piedra ante la mirada de su hermano Tanamilla. Su figura petrificada queda junto al estero Nigue, pero luego se desplaza mar adentro producto de las fuerzas telúricas, hasta donde se dirigen en botes los miembros de las congregaciones rituales de las comunidades de Mehuín y Queule para rendirle culto.

Su caso ilustra, con particular nitidez, que el devenir en ancestro no depende de los atributos personales de los protagonistas, sino de la posición de liminalidad en tránsito entre lo inmanente y lo trascendente, donde la fluidez propia del espíritu se encuentra contenida por la constancia y permanencia de los elementos. El mundo andino es pródigo en ejemplos similares. En la comunidad de Calca, en el valle sagrado de los incas, los espíritus tutelares del lugar, llamados Pitusiray y Sawasiray, son dos jóvenes amantes que han quedado convertidos en montañas como castigo por una relación adúltera (Sánchez Garrafa 1992). En Pisac, la N $u s t a$ (princesa) y el Apu Linle se han transformado en los espíritus intercesores luego de quedar petrificados en las alturas del entorno, por una imprudencia de ella. Contra las advertencias de su padre, la joven volteó la vista mientras sus pretendientes se disputaban su mano construyendo un puente. Hoy ambos cuidan los destinos del pueblo desde las alturas de los cerros.

\section{Identidades Cúlticas}

El culto a los Ngen Mapu especifica las identidades religiosas mapuche williche; distingue y cohesiona a los miembros de las congregaciones 
en torno a la figura de los mediadores y vincula a las organizaciones rituales, generando relaciones de solidaridad según la afinidad en la fe. Al igual que el mundo andino (Chacama 2003) estas "identidades espirituales" sirven de base para la organización social a nivel territorial, permitiendo la definición de unidades sociales y alianzas (Moulian 2009). Las congregaciones rituales son instancias por las que se despliegan procesos de reclutamiento social para hacer frente a las necesidades y movilización política ante los conflictos que afectan a las comunidades.

En el área de lago Ranco y los llanos del río Bueno, los miembros de estas congregaciones rituales se denominan a sí mismos kamasko, kamaska, título que se ostenta con un sentido identitario. No obstante, el término no es propio del mapudungun, por lo que no se encuentra registrado en los diccionarios de esta lengua (Augusta 1992 [1916]; Cañas 1911; Erize 1960; Febres 1975 [1764]; Havestadt 1777; Valdivia 1887 [1606]). Se trata de una voz de origen quechua cuya apropiación pone en evidencia los paralelismos culturales de los que aquí informamos. El lexema deriva de la raíz semántica kama, que denota poder y autoridad y conforma una serie de palabras del campo político y religioso. Entre estas kamaq, que alude al creador o espíritu vitalizante; kamaquen, que denota la fuerza vital que da energía y movimiento a las personas, y kamasqa que designa a quienes reciben el kamaquen de un kamaq particular, al que rinden culto. Kamaska es, en la definición de Taylor (2000:6), "un hombre que se beneficia por los poderes transmitidos por una huaca". El término implica, por lo tanto, un tipo de identidad espiritual y cúltica constituida a partir de la transferencia del principio vital desde las entidades numinosas hacia los seres humanos, lo que genera relaciones de dependencia sancionadas ritualmente.

El uso de esta voz asume un sentido similar entre los mapuche williche de lago Ranco y río Bueno. Aquí la expresión "kamasko"/"kamaska" designa a los miembros de congregaciones rituales que le rinden culto a los espíritus de Wenteyao, Kintuante y Juanico. Estos espíritus tutelares no solo cuidan los intereses y prodigan favores a los fieles, sino son proveedores de newen, fuerza vital que se transfiere a quienes los visitan. $\mathrm{Su}$ institucionalidad opera sobre la base de representaciones pneumatológicas análogas a las existentes en el mundo andino en relación con las transformaciones del espíritu (ancestralización), sus emplazamientos en el paisaje (rocas, cuevas) y la transferencia de energía vital que opera, preferentemente, por contigüidad. Por lo mismo, las moradas de los Ngen Mapu son centros de peregrinaje hasta donde acuden las congregaciones rituales para propiciar con ofrendas la protección de los espíritus, recibir su fuerza y llevar hasta sus comunidades elementos significantes de su presencia que se toman de su entorno.

El viaje de los kamaskos hasta la residencia de los espíritus tutelares asume la forma de un ritual solemne, que se realiza previo a las rogativas que en esta área se organizan anualmente. Su propósito es informar a los intercesores que se encuentran preparando la realización de las ceremonias comunitarias, invitarlos a participar en ellas y propiciar su ayuda. Antes de ingresar a su espacio, piden autorización para acceder a su presencia. Llevan muday (chicha de trigo), cereales, harina tostada, harina producida con los frutos de sus cementeras, corderos o gallinas que son ofrendados en su nombre. Del entorno de la casa de Juanico y Kintuante los kamaskos toman una rama de laurel que pondrán en el rewe de sus respectivos campos de rogativa. Estas "ramitas" son sometidas a particulares atenciones rituales. Las riegan con la sangre de los animales sacrificados y alimentan con harina y muday, para ser devueltas a su lugar de origen una vez concluida la ceremonia. En el caso de Wenteyao, quien habita en el mar, troncos de coyofe o cochayuyo cumplen similar función.

Este patrón de peregrinaje se desarrolla de manera análoga en el mundo central andino, donde la visita a los ancestros emplazados en el paisaje se inscribe dentro del ciclo festivo anual. En Pisaq, por ejemplo, durante agosto se acostumbra visitar a la Ñusta y el Apu Linle, espíritus tutelares, situados en las montañas, hasta donde ascienden los comuneros para hacerles sus pagos. Esta actividad se inscribe dentro de la fiesta de la situa, consagrada a la renovación de energías (Rozas y Calderón 2000), que se desarrolla en este mes de transición del secano hacia las primeras lluvias, cuando se considera que la tierra se abre y demanda ser alimentada ritualmente. En la comunidad de Rayampata, de la provincia cusqueña de Calca, la visita a Pitusiray y Sawasaray se realiza durante la fiesta del linderaje que aquí se realiza en noviembre. Durante esta los comuneros recorren los hitos de su territorio, subiendo hasta la morada de los 
espíritus ancestrales con flores, kintus (ofrendas de coca) y "despachos", como denominan a los pagos rituales (Thornton 2011). De la antigüedad de la devoción a estas figuras da testimonio Guamán Poma de Ayala (1980 [1613]) quien informa de los sacrificios que les ofrecían los incas (Figura 4).

Entre la población aymara también se encuentra arraigado este sistema cúltico. Así lo hemos podido ver en Calana, en las afueras de Tacna, donde se mantiene vigente la fe en dos espíritus petrificados conocidos como Pacha y Mama (hombre y mujer). Su historia, expresada con variantes, reproduce una trama narrativa ampliamente difundida en el espacio central andino. Un anciano andrajoso visita el pueblo, siendo rechazado por la mayoría de sus habitantes salvo una pareja que lo atiende y le da de comer. El hombre les advierte que deben marcharse para salvar sus vidas, porque una desgracia se abalanzará sobre su comunidad y les señala que no pueden volver la vista atrás. La pareja emprende la huida pero cae en la tentación de mirar lo que sucede y queda petrificada en el cerro. Hasta hoy

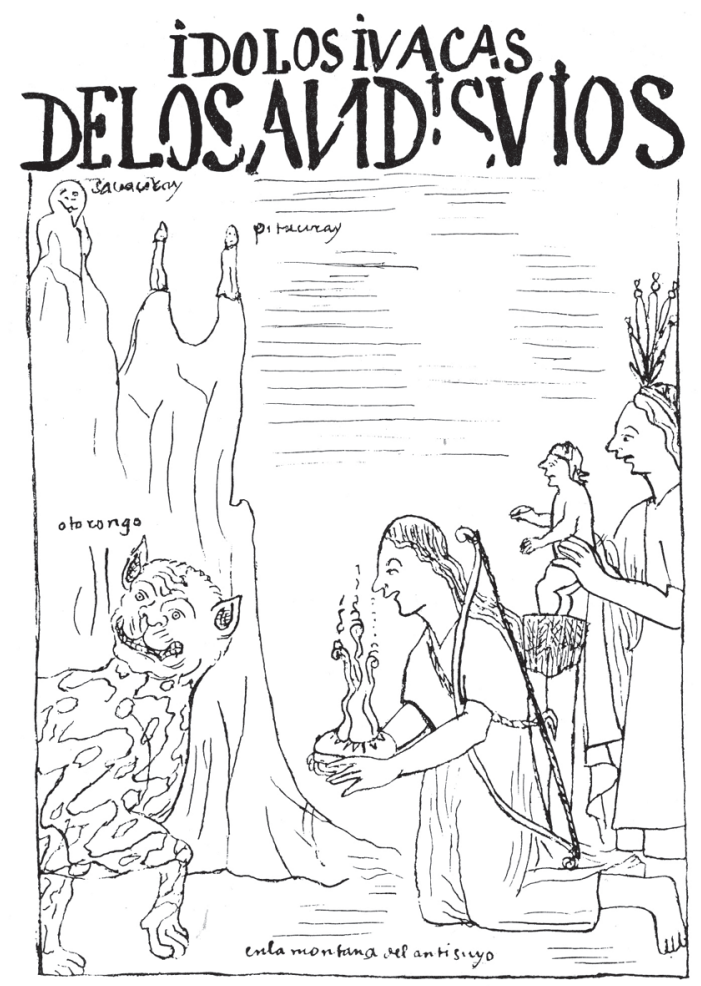

Figura 4. Representación del culto inca a Pitusiray y Sawasaray, según Guamán Poma.

Depiction of the Inca worship to Pitusiray and Sawasaray according to Guaman Poma. los habitantes de Calana hacen una romería para esperar con ellos la llegada del Viernes Santo. Suben de noche hasta la cima del cerro Arunta, donde se encuentra la mujer. De regreso, ya de alba, pasan donde el hombre, cuya piedra está en la base de la colina. Ambas rocas tienen una boca en la parte inferior, por la que se las alimenta, porque al igual como en el mundo mapuche, se considera que en su interior hay espíritus vivos y poderosos que demandan atención.

\section{Correlatos Simbólicos}

Los espacios de emplazamiento de los ancestros espiritualizados son hitos que organizan el campo de referencias geográficas de las comunidades andinas. Los caminos que conducen a ellos se valoran como vías de acceso al conocimiento y el poder, necesarios para la mantención del equilibrio entre el ser humano y su entorno. Los espíritus tutelares que allí tienen su asiento se consideran proveedores de la energía vital que anima a las personas y fertiliza la tierra y los animales, la que debe ser propiciada mediante ofrendas y oraciones cada nuevo ciclo productivo. Esta acción ritual se concibe como una comunicación entre distintos niveles de realidad por los que se produce la interacción y el intercambio de dones. Nos encontramos, por lo tanto, ante un complejo marco de representaciones que hace posible el funcionamiento de este sistema cúltico, cuyos paralelismos expresan no solo una lógica cultural común, sino paradigmas cosmovisionarios (metamodelos) compartidos.

Los accidentes naturales donde se consideran emplazados los espíritus ancestrales operan como significantes de órdenes simbólicos en los que se anudan diversos niveles de sentido. En primer término refieren a estos mediadores, pero se asocian también las dimensiones del espacio subyacente que las contiene. En el dominio de las implicancias de su sistema de interpretantes se encuentran las estructuras del mundo donde ellas se sitúan. Las cuevas, rocas o fuentes de agua donde se encuentran emplazados se conciben así como portales que conectan y brindan el acceso a otros estratos del universo. La topografía, por lo tanto, presenta codificada las claves de referencia de la cosmografía. En ella encontramos proyectada modelos del mundo que resultan similares en el espacio Centro y Sur Andino, caracterizados por una estructura estratigráfica vertical y articulación 
circular. En el caso mapuche este se compone de los niveles de Wenu Mари (mundo de arriba), Nag Мари (mundo intermedio en el que habitan los seres humanos) у Minche Mapu (mundo inferior). En el caso del mundo quechua, de Hanan Pacha, Kay Pacha y Uku Pacha.

La presencia de cuevas, lagos y rocas como portales o vasos comunicantes en los procesos de ancestralización deja en evidencia la articulación circular de estos niveles en ambas áreas culturales. En ellas el movimiento hacia el interior es una vía de desplazamiento hacia el mundo espiritual, asociado con el plano superior del universo. Ello permite a los ancestros actuar como intermediarios o mediadores ante las deidades superiores. La recurrencia en las variantes de este proceso de convertirse en ancestro y la presencia de voces comunes para referir identidades rituales asociadas a su culto refuerzan nuestra tesis. El análisis de los procesos de ancestralización muestra la convergencia de representaciones en torno al paisaje, la fenomenología del espíritu (pneumatología) y las prácticas cúlticas comunes al espacio Centro y Sur Andino.

La desaparición de las poblaciones indígenas en el centro y noroeste argentino complejizan el estudio de estos órdenes de representación en este vasto espacio intermedio, el que debe hacerse por medio de indicios y supervivencias. No obstante, debe destacarse que la cultura popular de este territorio registra una profusa narrativa sobre lugares poderosos y personajes encantados que viven en lagunas, cerros y piedras (Vidal 1984). La relación entre los espacios naturales y los espíritus ancestrales se encuentra consignada de manera recurrente en sus relatos. Entre los de origen Huarpe, se puede referir la historia Los tres manantiales de Laja (Estrada 1985). Esta atribuye a la acción del dios Taimenta la creación de vertientes en memoria y representación de tres jóvenes indígenas muertos en un drama pasional. La toponimia de la provincia de San Juan muestra el emplazamiento de esta narrativa en espacios localizados. Así sucede, por ejemplo, con cerro Pie de Palo, donde se encuentra transfigurado un antiguo cacique Huarpe, convertido en espíritu tutelar. Otro tanto ocurre en las termas de Pismanta donde se considera quedó atrapado en una cueva el cacique homónimo, principal Angualasto, cuyas lágrimas habrían dado origen a las aguas calientes del lugar.

La continuidad y dispersión de estos motivos en el territorio sugiere la existencia de metamodelos cognitivos panandinos y perfila a los Andes como un corredor por el que se desplazan símbolos, ideas y capitales culturales. El nivel de complejidad en que se manifiestan los paralelismos no permite su explicación en términos naturalistas, sino histórico-culturales. Al respecto se debe destacar que las concordancias son recursivas, puesto que incluyen rasgos semióticos formales (sintácticos), ideacionales (semánticos) y pragmáticos. Estas asumen un carácter sistemático en tanto se expresan en nodos simbólicos que integran múltiples dimensiones del sistema religioso cosmovisionario y comprometen complejas tramas de sentido y órdenes de representación. Bien nos encontramos aquí ante un indicador de relaciones de cotradición que invita a repensar las áreas culturales en la macrorregión andina, de modo de hacer más nítida la participación de la cultura mapuche williche en ella. Bien nos situamos ante la evidencia de relaciones de antigua data entre los sistemas de representaciones que presentan un origen familiar común, lo que sugiere la existencia de linajes cosmovisionarios, cuyo análisis debe realizarse de modo contrastante, puesto que constituyen un sistema de variantes y transformaciones.

Agradecimientos. Expresamos nuestra gratitud al Fondo de Desarrollo Científico y Tecnológico (Fondecyt) que ha hecho posible nuestra investigación mediante el Proyecto 1120139, "La impronta andina en la cosmovisión mapuche williche". A la Dirección de Investigación de la Universidad Austral de Chile por su respaldo por medio del proyecto DID-S 2 2012, "La alimentación de las almas en las áreas norte y centro andinas". A los colegas de la Universidad Nacional San Antonio Abad de Cusco, Washington Rozas, Ricardo Valderrama, Carmen Escalante y Jorge Flores Ochoa por sus valiosas orientaciones en el área. A los evaluadores anónimos, cuyos comentarios han permitido enriquecer este trabajo. 


\section{Referencias Citadas}

Adán, L., R. Mera, M. Becerra y M. Godoy 2004. Ocupación arcaica de territorios boscosos y lacustres de la región precordillerana andina del centro-sur de Chile. El sitio Marifilo 1 de la Comunidad de Pocura. Chungara Revista de Antropología Chilena, Volumen Especial, Tomo II, pp. 1121-1136.

Alonqueo, M. 1993. Mankian. En Introducción a la Religiosidad Mapuche, editado por R. Foerster, pp. 165-166. Editorial Universitaria, Santiago.

Álvarez-Santullano, P. y C. Contreras 1991. Cosmovisión huilliche a través del credo y el ritual. Actas Coloquio sobre Culturas Indígenas, pp. 45-53. Universidad Católica de Temuco \& Universidad de La Frontera, Temuco.

Augusta, F. 1992 [1916]. Diccionario Mapuche-Español. Seneca Ediciones, Santiago.

Cañas, A. 1909. El Culto a la Piedra en Chile y en otras Partes del Mundo. Imprenta Cervantes, Santiago.

----1911. Estudios de Lengua Veliche. Imprenta Barcelona, Santiago.

Carrasco, H. 1989. El Sistema Funcional de los Mitos Mapuches. Tesis para Optar al Grado de Doctor en Literatura. Universidad de Chile, Santiago.

Comisión de Trabajo Autónomo Mapuche 2003. Estudio del pueblo mapuche wijice. Informe de la Comisión de Verdad Histórica y Nuevo Trato. Volumen III, Tomo III. http://biblioteca. serindigena. org/libros_digitales/cvhynt/v_iii/t_iii/v3_t3_chaurakawin.html (enero 2013).

Condori, B. y R. Gow 1976. Kay Pacha. Centro de Estudios Rurales Andino Bartolomé de las Casas, Cusco.

Cruz, P. 2006. Mundos permeables y espacios peligrosos. Consideraciones acerca de punkos y qaqas en el paisaje altoandino de Potosí, Bolivia. Boletín del Museo Chileno de Arte Precolombino 11:35-50.

Chacama, J. 2003. Identidad espiritual y organización social en los andes centrales. Revista de Historia Indígena 7:139-158.

Dillehay, T. 1990. Araucanía: Presente y Pasado. Andrés Bello, Santiago.

----1998. Felines, patronyms, and history of Araucanians in the southern Andes. En Icons of Power: Feline Symbolism in the Americas, editado por N. Saunders, pp. 203-227. Routlegde, London and New York.

----2004. Monteverde: un Asentamiento Humano del Pleistoceno Tardio en el Sur de Chile. LOM, Santiago.

----2011. Monumentos, Imperios y Resistencia en los Andes. Ocho Libros, Qillqa y Venderbilt University, Santiago.

Dillehay, T. y A. Gordon 1998. La actividad prehispánica de los incas y su influencia en la Araucanía. En La Frontera del Estado Inca, compilado por T. Dillehay y P. Nehterly, pp. 183-196. Fundación Alexander von Humboldt y Editorial Abya-Yala, Quito.

Duviols, P. 1973. Un symbolisme andin du doble: la lithomorphose de l'ancestre. Actes de XLII Congrès International des Américanistes Vol VI, pp. 359-364. Société des américanistes de Paris, Paris.
Eliade, M. 1970. Tratado de Historia de las Religiones. Ediciones Cristiandad, Madrid.

Erize, E. 1960. Diccionario Comentado Mapuche-Español. Cuadernos del Sur. Instituto de Humanidades. Universidad Nacional del Sur, Buenos Aires.

Estrada, M. 1985. Leyendas y Supersticiones Sanjuaninas. Editorial Tucuma, Buenos Aires.

Febres, A. 1975 [1764]. Arte de la Lengua del Reyno de Chile. Cabildo, Vaduz-Georgetown.

Foerster, R. 1993. Introducción a la Religiosidad Mapuche. Editorial Universitaria, Santiago.

Foerster, R. y H. Gunderman 1996. Religiosidad mapuche contemporánea. Elementos introductorios. En Etnografía. Sociedades Indígenas Contemporáneas y su Ideología, editado por J. Hidalgo, V. Schiappacasse F., C. Aldunate del S. y P. Mege R., pp. 189-240. Editorial Andrés Bello, Santiago.

Galdames, L. 1987. Vitalidad de la piedra y petrificación de la vida: Notas sobre la mentalidad andina. Diálogo Andino 6:129-143.

Gissi, N. 1997. Aproximación al Conocimiento de la Memoria Mapuche Williche de San Juan de la Costa. Tesis para Optar al Título de Antropólogo. Universidad de Chile, Santiago.

Grebe, M. 1986. Algunos paralelismos en los sistemas de creencia mapuche: los espíritus del agua y la montaña. Cultura, Hombre y Sociedad 3:143-154.

----1995-1996. Continuidad y cambio en las representaciones icónicas: significados simbólicos en el mundo sur andino. Revista Chilena de Antropología 13:137-154.

----1996. Patrones de continuidad en el mundo surandino: creencias y cultos vinculados a los astros y los espíritus de la naturaleza. Cosmovisión Andina pp. 205-220. Centro de Cultura, Arquitectura y Arte, La Paz.

----2002. Los mapuche en el contexto del mundo andino: algunas perspectivas interculturales. Lengua y Literatura Mapuche 10:23-34.

Guamán Poma de Ayala, F. 1980 [1613]. Nueva Corónica y Buen Gobierno. Biblioteca Ayacucho, Caracas.

Guevara, T. 1911. Folklore Araucano. Imprenta Cervantes, Santiago.

Havestadt, B. 1777. Chiledungu. Typis, Teubneri.

Jemio, L. 2009. Relatos de Montaña como Articuladores del Pensamiento del Pueblo de Sajama y del Pueblo de San José de Cala del Departamento de Oruro. Instituto de Estudios Bolivianos \& Universidad Mayor San Andrés, La Paz.

Jung, C. 1994. Arquetipos e Inconsciente Colectivo. Paidós, Barcelona.

Kaulicke, P. 2003. Memoria historiografiada y memoria materializada. Problemas en la percepción del pasado andino preeuropeo. Estudios Atacameños 26:17-34.

Koessler, B. 1962. Tradiciones Araucanas. Tomo I Instituto de Filología. Facultad de Humanidades y Ciencias de la Educación. Universidad Nacional de La Plata, La Plata. 
Martínez, G. 1976. El sistema de uywiris en Isluga. En Homenaje al Dr. Gustavo le Paige, SJ, editado por H. Niemeyer, pp. 255327. Universidad del Norte, Antofagasta.

Moulian, R. 2005. Tiempo de Lepün. Universidad Austral de Chile \& Programa Orígenes, Valdivia.

Moulian, R. (dir.) 2008. Ngen rupu/ El camino del Ngen. Universidad Austral de Chile \& Consejo Nacional de la Cultura y las Artes, Valdivia.

----2009. Ailla \& rewe. Mediación ritual de la sociedad mapuche williche. Revista Austral de Ciencias Sociales 17:57-74.

----2012. Metamorfosis Ritual: desde el Ngillatun al Culto Pentecostal. Kultrun \& Universidad Austral de Chile, Valdivia.

Moulian, R. y C. Valdés 2001. Abuelito Huenteao, Mito y Ritual. Consejo Nacional de la Cultura y las Artes \& Universidad Austral de Chile, Valdivia.

Nielsen, A. 2010. Las chullpas son ancestros: paisaje y memoria en el altiplano sur andino (Potosí, Bolivia). En El Hábitat Prehispánico, editado por M.E. Albeck, M.C. Scattolin y A. Korstanje, pp. 329-349. Universidad Nacional de Jujuy, Jujuy.

Otto, R. 2001. Lo Santo. Lo Racional y lo Irracional en la Idea de Dios. Alianza Editorial, Barcelona.

Peirce, Ch. 1974. La Ciencia de la Semiótica. Ediciones Nueva Visión, Buenos Aires.

Quezada, A. 2002. Huentellao. Universidad de Los Lagos \& Liceo Eleuterio Ramírez, Osorno.

Regalado, L. 1996. Espacio andino, espacio sagrado: visión ceremonial del territorio en el período incaico. Revista Complutense de Historia de América 22: 85-96.

Rozas, W. y M. Calderón 2000. La renovación: una interpretación de los rituales de agosto. En Desde Afuera y desde Dentro: Ensayos de Etnografía e Historia de Cusco y Apurimac, editado por L. Millones, H. Tomoeda y T. Fuji, pp. 317-352. National Museum of Ethnology, Osaka.

Rubina, C. 1992. La petrificación en el manuscrito de huarochirí. Mester 21:71-82.

Salomon, F. 1995. The beautiful grandparents: Andean ancestor shrines and mortuary ritual as seen as through colonial records. En Tombs for the Living: Andean Mortuary Practices, editado por T. Dillehay, pp. 315-353. Dumbarton Oaks, Washington DC.

----1998. Collquiri's dam: The colonial re-voicing of an appel archaic. En Native Traditions in Postconquest World editado por E. Hill y T. Cammings, pp. 265-293. Dumbarton Oaks, Washington DC.
Sánchez Garrafa, R. 1992. Pitusiray y Sawasaray: mitos de alianza y restauración cósmica. Anthopologica 10:277-295.

Sarmiento de Gamboa, P. 2001. Historia de los Incas. Miraguano, Madrid.

Schindler, H. 1996. Amüllpullun: un rito funerario de los mapuche chilenos. Lengua y Literatura Mapuche 7:165-180.

Schindler, H. y M. Schindler 2006. La Piedra Santa de Lumaco. En Cuatro Estudios Acerca de la Espiritualidad Mapuche, editado por H. Schindler, pp. 11-67. Verlagsbuchhandlung, Munchen.

Sebastiani, C. (comp.) 1989. Fabulaciones de Tres Mundos. Mitos, Leyendas, Tradiciones y Cuentos Folklóricos Peruanos. Ediciones Pedernal, Lima.

Silva, O. 1977-1978. Consideraciones acerca del período inca en la cuenca de Santiago (Chile Central). Boletín $\mathrm{N}^{\circ} 16$. Museo Arqueológico de La Serena, La Serena.

Taylor, G. 1987. Ritos y Tradiciones de Huarochiri. Instituto de Estudios Peruanos, Lima.

----2000. Camac, Camay, Camasca y otros Ensayos sobre Huarochiri y Yauyos. Centro de Estudios Regionales Andinos Bartolomé de Las Casas \& Instituto Francés de Estudios Andinos, Lima.

Taype, C., L. Puma y F. Aroni 2011. Cuentos, Leyendas y Maravillas del Qorilazo. Taller Gráfica Impresiones, Juliaca.

Thornton, G. 2011. Las montañas respiran. La cosmovisión de la Comunidad Rayampata representada a través del mito Pitusiray Sawasiray. Independent Study Project (ISP) Collection. Paper 1182. http://digitalcollections.sit.edu/ isp_collection $/ 1182 /$ ?utm_source=digitalcollections.sit. edu\%2Fisp_collection\%2F1182\&utm_medium=PDF\&utm_ campaign=PDFCoverPages (enero 2013).

Toro, C. 2007. Mitos y Leyendas de la Sierra. Fondo Editorial Cultura Peruana, Lima.

Urbano, H. 1981. Wiracocha y el Ayar. Héroes y Funciones en las Sociedades Andinas. Centro de Estudios Rurales Andinos Bartolomé de Las Casas, Cusco.

Valdivia, L. de 1887 [1606]. Arte y Gramática General de la Lengua que Corre en Todo el Reyno de Chile, con un Vocabulario y Confessionario. Ausgabe von Platzmann, Leipzig.

Vera, D. (ed.) 2002. Hijas de Kavillaca. Tradición Oral de Mujeres de Huarochirí. Ediciones Flora Tristán, Lima.

Vidal, B. 1984. Cuentos y Leyendas Populares de Argentina. Volumen VII. Ediciones Culturales Argentinas, Buenos Aires.

Villanés, C. 1992. Los Dioses Tutelares de los Wankas (Mitos y Leyendas Peruanos). Miraguano Ediciones, Madrid. 


\section{Notas}

1 Por su función y localización, los gnen mapu se distinguen de los püllu, como se denomina a los espíritus individuales de los antepasados, que residen en el Wenu Mapu, el mundo de arriba o en la Külche Mapu, tierra de las entrañas, hasta donde se desplazan tras la muerte. Si bien los püllu también se mantienen en interacción con sus descendientes en la tierra y se manifiestan por medio de fenómenos atmosféricos (vientos, tormentas, truenos, relámpagos), geológicos (erupciones volcánicas, temblores) y en los sueños se sitúan de modo regular en un espacio alterno. Los espíritus de la naturaleza, conocidos genéricamente como gnen (dueños), en tanto, poseen un carácter abstracto y multilocalizado que los relaciona con los elementos (el agua, el bosque, la montaña), sobre los que tienen un carácter tutelar. Si bien suelen adquirir manifestaciones concretas y encarnarse en diversas especies animales, no se caracterizan por su individuación, como es el caso de los ngen mapu.

2 Hemos participado en peregrinajes rituales a la 'casa del Abuelito Wenteyao’ en Pucatrihue los años 1999, 2000, 2006; acompañamos a la congregación de Nolguehue a la morada 'Juanico' el 2001, 2003, 2005, 2008; con los mayores de la comunidad de Maihue llegamos ante Kintuante el 2004, 2005, 2006, 2007, 2008; asistimos a la fiesta de la 'Piedra Santa de Lumaco' los años 2006 y 2011.

3 Una objeción habitual al emplear las analogías en las formas simbólicas como indicador de relaciones interculturales es la posibilidad que estas semejanzas expresen estructural o tendencialmente universales de la condición o experiencia humana. Por lo mismo, planteamos la comparación a nivel de paradigmas cosmovisionarios, porque las teorías naturalistas como las de Jung pueden explicar las semejanzas a nivel de las formas simbólicas, pero no de complejas tramas de sentido. 4 Al respecto, debe considerarse las prácticas de momificación y la construcción de monumentos fúnebres como medios de ancestralización.

5 El culto a las montañas en el área central andina es un ejemplo extendido de ancestralización de los elementos del paisaje, marcado por el animatismo, es decir, la animación y personificación de los elementos de la naturaleza. El culto de los ngen mapu se fundamenta en representaciones animistas. Para una distinción entre las concepciones animatistas y animistas, ver Grebe (1986). 